\title{
Towards an inclusive digital literacy: An experimental intervention study in a rural area of Brazil
}

\author{
Viviane Brito Nogueira, et al. [full author details at the end of the article]
}

Received: 13 December 2020 / Accepted: 10 August 2021 / Published online: 3 September 2021 (c) The Author(s), under exclusive licence to Springer Science+Business Media, LLC, part of Springer Nature 2021

\begin{abstract}
About half of the world's population remains without access to internet in an era of digital transformation. In this study, we aimed to investigate the impact of implementing the use of logic and mathematics through digital literacy on a population of elementary school students in a town in Northeast Brazil. In a non-randomized experimental longitudinal intervention study, 5th-grade students were followed during one semester. They underwent observational testing during class with the use of scales to evaluate their activities in a digital environment, and they were evaluated with respect to their ability to use digital devices. A logic/math assessment was applied prior to and at the end of the course for intervention group and compared to a control group. Questionnaires were used to assess the educators', legal guardians' and students' perceptions on digital habits and their respective sociodemographic features. The intervention consisted of a 16-h long course developed consisting of 8 2-h long classes which focused on digital technology, digital culture, and computational thinking. The students had a strong interest in the classes. Although some students did not have prior contact with computers, their development was outstanding. Digital literacy competencies and technology-use behavior increased throughout the semester independent of family income and use of digital devices at home. Students progressively improved their interaction with the computer (e.g. touchpad and typing skills) and their confidence in the digital environment. Students' scores on the logic/math assessment showed significant improvement. This was not observed in the control group, demonstrating the importance of this type of intervention even with one provided by a $16-\mathrm{h}$ course.
\end{abstract}

Highlights

- 16 hours of a digital literacy course can help improving math and logic skills

- Digital confidence of 5th-grade students increased throughout the semester

- Students' computer interaction improved independent of digital culture at home

- Digital classes keep students motivated in a rural school of a developing country

- We present a digital literacy course suitable to be applied to other digital exclusion locations 
Keywords 5 th-grade $\cdot$ Digital divide $\cdot$ One computer per student $\cdot$ Middle-income country $\cdot$ Digital literacy course

\section{Introduction}

Disruptive digital technologies (e.g., machine learning, crowdsourcing) have prompted new forms of daily practice (Flavin, 2017) and their impacts on the economy and government affect the society at different levels. The new era induced by digital transformation requires early investment in young people as readiness is crucial to accompany the constant change in all societies (Chowdhry et al., 2020). For one to be prepared within this new paradigm, it is essential to develop skills in the digital world and strengthen interest in the Science, Technology, Engineering and Mathematics (STEM) fields (Bekker et al. 2015).

Digital exclusion has become one of the multiple forms of social segregation and it is present in developed and underdeveloped countries. There is still a lack of practical and plausible digital literacy strategies for rural and/or remote scenarios. As a result, the digitally excluded population may fail to take advantage of online services that could overcome geographic barriers e.g., online education, health services, shopping, tax/bureaucracies transactions, transport, and digital economy (Freeman \& Park, 2015; Park, 2016).

Furthermore, this has been well documented with the ongoing pandemic of SARSCoV2, whose impact in education has recently been unveiled. Students in both Brazil and the United States are being left behind because of the lack of access to computers and to the internet. There is potential to adopt e-learning in some locations. Nevertheless, inequality and the digital divide are increased when part of the population has neither devices nor appropriate training to engage in these changes or availability to access the internet (Bakker \& Wagner, 2020). This demonstrates the urgency for pragmatic solutions to digital literacy in this time of globalization.

There is a school of thought that treats digital inclusion as a way for other inclusions to occur, focused not only on the technical use of new tools (Park, 2016). To offer the necessary skills to access internet content critically and to be able to analyze, evaluate, or to produce it, there is a need for literacy in regards to digital technology, digital culture, and computational thinking (Brazilian Ministry of Education, 2018). We aimed to evaluate whether the introduction of digital technology in the classroom in elementary school would improve STEM skills such as computational thinking and familiarity with environment and digital devices and whether it would promote empowerment to perform logical activities autonomously. Overall, this study sought to establish a safe and collaborative environment for children to have access to digital technologies. Our research question was whether $16 \mathrm{~h}$ of digital literacy, presented in eight 2-h classes, could positively influence the logical reasoning of students in the 5th-grade. Herein we present an adequate digital literacy strategy for remote regions, with reuse of previously abandonedlaptops. 


\section{Theoretical background}

\subsection{Is digital literacy real for those born after the internet? The social classes gap in low income populations}

From an educational perspective, digital literacy embraces the technical, cognitive, and social-emotional aspects of learning with digital technologies (online and offline) in a developmental way. For a digitally literate individual, it is easy to adapt to emergent technologies and promptly infer the semiotic language for new types of communication. Digital natives are the generation of people born from 1980 (Prensky, 2001). They are likely more engaged in digital technologies, with the urge to obtain information quickly, using visuals over texts compared to past generations. A combination of historical events and their associated phenomena constitute a generational gap (Parry \& Urwin, 2011). Generation $Z$ is described as those born in the mid-1990s through the late 2010s. For Generation $\mathrm{Z}$ it is conventional to interact and communicate in an environment that is connected at all times (Turner, 2015). Interestingly, even adults born after the internet that use digital devices daily can be taught digital literacy as a mean for learning $(\mathrm{Ng}, 2012)$, as they could be not familiar with educational technologiespointing to the need for school programs.

Although the digital world is part of the everyday life of the digital-literate people and the new Generations are usually immersed in it, digital literacy is not a reality in many regions around the globe. Approximately $47 \%$ of the world population is offline. Most of the offline population live in low to middle developed countries-Europe has the highest and Africa has the lowest number of people online (International Telecommunication Union, 2019). There is solid research pointing to a link between social and digital exclusion (Helsper, 2012; Park, 2016; Witte \& Mannon, 2010).

Brazil is a developing country, where rural-urban locations, socio-economic class and social exclusion are decisive factors for low levels of learning, e.g., school accessibility, adult functional illiteracy and dropping out of school (Hickey \& Hossain, 2019). The Internet reaches $74.9 \%$ of Brazilian households, however this proportion differs among different regions of the country. The Brazilian Northeast is the least connected region at 52.3\% (IBGE, 2019). In the municipality of Pureza (State of Rio Grande do Norte), where this study was conducted, $45.5 \%$ of its 2019 population were beneficiaries of a conditional cash transfer programme from the Brazilian Federal Government, called Bolsa Família - a program that provides a maximum of $\$ 100$ per month per family (Brazilian Ministry of Social Development, 2020) demonstrating the need for income assistance and therefore people are more likely not to have easy access to computers or internet. In this municipality low scores of learning and poor school infrastructure are risks for the local population (Bezerra et al., 2021).

\subsection{Digital engagement in the rural communities}

The digital economy and government-reshaping approaches through novel methods of communicating and delivering public services are central in the social organization based on digital connection. When communities are remote and thinly 
distributed, the probability of having no or very poor broadband connectivity is high. Digital participation limitation is revealed in the urban-rural divide (Williams et al., 2016). Frequently, people residing in rural areas are more affected by social exclusion parameters such as age, income and educational level-and these social disparities are likely to be a more critical problem than infrastructural needs such as access to the internet (Basu \& Chakraborty, 2011).

Nevertheless, there is ample evidence of the benefits to the rural population to go online. Continuous interactions between farmers and townspeople appear to be significant for sustaining the local jobs and economy, and a strong sense of belonging in a rural community (McManus et al., 2012). Research on the benefits of educational investment shows that those with higher skill levels (including the digital ones) tend to practice more active citizenship and to enjoy better health (Psacharopoulos \& Patrinos, 2018; Schuller, 2004). Furthermore, the diffusion of digital skills can be a socio-economic development strategy. There is a growing rise in the search for professionals who master Information Technology (IT) abilities, resulting in increased employability (Karpati, 2011) which can include remote-jobs, applicable to the rural population.

\subsection{What counts for the effective appropriation of digital skills?}

Effectiveness for digital inclusion and/or literacy courses are complex. Currently, middle and low-income countries are still facing the challenge of the so-called learning crisis, addressed in the Sustainable Development Goal 4 of the United Nations which emphasizes quality and equality. This learning crisis is broad and irregularly spread, varying among countries, classes, gender and social groups (World Bank, 2018). Approaching this crisis is central to the organization of digital literacy courses like the one proposed in this study. Here we discuss the issues related to the effective appropriation of digital skills at the government-, school-, teacher-, and student-level.

\subsubsection{Government-level}

Political commitment to education is directly related to the success in schooling quality (Hickey \& Hossain, 2019). The immediacy approach, often from an access point of view, in education reforms does not bring long term profits, in contrast to focusing on the quality of learning. Much was tried, and little was effective, at quality reforms in Brazil, this scenario was aggravated by difficulty in measuring results (Nelson, 2007).

The "One Computer per Student" project (OCS) was a widely criticized Brazilian government project implemented in 2008. The government provided every school student a laptop with the goal of introducing digital classes into the general curriculum from 1st to 9th grade. Despite the huge financial investment, in most Brazilian states the computers have been abandoned. This unsuccessful outcome was due to deficiencies in the infrastructure for its implementation (the management of processes and training of teachers) and to structural aspects of the project (Echalar \& 
Peixoto, 2017). However, in this study, we reused those computers to test the hypothesis that digital literacy when appropriately planned could be quickly attained.

\subsubsection{School-level}

The most common problems at schools are infrastructure and electrical networks; followed by internet connection, inadequacies in both classroom environment and storage of equipment, absence of human resources for technical support, and equipment acquisition and replacement (Andriola \& Gomes, 2017). Additionally, keeping students and teachers equipped and motivated for teaching and learning are central in the process of digital skill empowerment. For this to be achieved, the school management needs to certify the development of a safe environment. In several schools, teachers received training for the OCS project, but there was a 50\% turnover of teachers hired (Nascimento et al., 2011). In other words, school management skills were low and school inputs failed to keep pace with expansion (Hickey and Hossain, 2019).

\subsubsection{Teacher-level}

Self-efficacy theory correlates the predictive value of an event's achievement with one's confidence to perform it (Bandura, 1977). This theory in the context of teacher efficacy is important to understand how teachers think they can control their teaching environment and what they consider students can learn (Siwatu, 2007). Teachers' efficacy beliefs and outcome expectancy increase as a result of interventions to prepare them to engage their students in computational thinking (Leonard et al., 2018).

The appropriation of digital technologies by teachers has been pointed out as the biggest challenge for the implementation of OCS project (Nascimento et al., 2011). Significant advances in the process of digital inclusion and instrumental use of digital technologies by teachers and especially students were observed. However, the underutilization of pedagogical resources and under-dimensioning or discontinuity of the teacher training process were decisive factors for the interruption of classes with digital technologies (Andriola \& Gomes, 2017). Indeed, teachers' previous knowledge was associated with student outcomes, e.g., teachers' mathematical knowledge was significantly related to student achievement gains in both first and third grades (Hill et al., 2005).

\subsubsection{Student-level}

A study in England showed that the combination of strong school-family relationships and high levels of school satisfaction provided a boost for young people's academic progress (Hampden-Thompson \& Galindo, 2017). The parental effort to support the student in the United States had a strong positive effect on student achievement, which was greater than the effect of school resources (Houtenville, 2007). Also in the United States, the quality of teacher-student relationship was associated with general school outcomes. Better student perceptions of the teaching 
atmosphere were significantly associated with lower student dropout rates of schools (Barile et al., 2012).

Although there are concordances between studies from developed and developing countries, it is necessary to focus attention on aspects such as poverty, child labor and familiar disruption to the reality of this study. The strong interdependence between poverty (and income disparity) and low educational achievement/fulfillment has long been reported (Reimers, 1999). In addition, child labor is still a reality in Brazil. Students who do not work have better school performance than students who work more than two hours a day. Students who work exclusively at home performed a little better than those who only work outside the residence. Students who work both inside and outside the house have the lowest achievement outcomes (Bezerra et al., 2009).

Moreover, the family environment in which the student lives is relevant. Chaotic households (crowded noisy homes with many distractions, poor structure and routines, and constant changes in family structure and residential moves) influence young children's developing discipline and ability to focus on school-related activities (e.g., completing homework) (Li-Grining, 2007; Vernon-Feagans et al., 2016) that are important for school success. A study with families living in low-wealth rural communities in the United States established that household disorganization is a mediator between early income poverty and academic achievement in kindergarten (Heberle \& Carter, 2020).

\subsection{Do logic, digital literacy and STEM relate? The course strategy}

At first, logical reasoning can be conceptualized as the process of using a rational, precise series of steps based on reliable mathematical procedures and given statements. Throughout history, the development of logic has provided a wide variety of logics ready for the purposes at hand in different disciplines (Vargas \& Stenning, 2019). The Brazilian Common Base National Curriculum (BNCC) clearly states that students in elementary school should "Develop logical thinking, research spirit and ability to produce convincing arguments, using mathematical knowledge to understand and act in the world". In this work, we developed this topic by teaching logic through computational thinking, that, by means of this, is possible for the individual to think about the basic steps to examine and identify a problem, and define the input and outputs and determine possible solutions (Türker \& Pala, 2020).

Secondly, a conceptual model for digital literacy was proposed in 2004 comprising five components: (1) photo-visual skills (understanding instructions from graphical layouts), (2) reproduction skills (using digital reproduction for creating novel relevant materials from previous ones), (3) branching skills (understanding from non-linear, hypertextual navigation), (4) information skills (figuring out information quality and veracity), and (5) socio-emotional skills (comprehending the rules of conduct on the internet and applying this comprehension in online communication) (Eshet-Alkali \& Amichai-Hamburger, 2004). Additionally, there are five types of literacy in the digital context: information, computer, media, communication and technology. Each one of these has technical (access, usage, 
navigation, development of content), cognitive (synthesis, evaluation, problem solving, critique, invent) and ethical (appropriate usage, assess truthfulness) perspectives (Chetty et al., 2018). Currently, there is no completely accepted definition for digital literacy and there are no universally comparable measures that thoroughly embrace its characteristics.

Thirdly, STEM has been recognized as a priority for education worldwide, being part of the 'public understanding of science' movement (Johnson et al., 2015). Studies have unraveled the potential benefits of ICT (Information and Communication Technology) literacy factors on students' academic outcomes on mathematics (Cheung \& Slavin, 2013; Erdogdu \& Erdogdu, 2015), sciences (Luu \& Freeman, 2011) and on both of these (Hu et al. 2018). Besides, there is a correlation between computational thinking skills and "thinking styles and academic success in mathematics class" (Durak \& Saritepeci, 2018). These studies provided evidence that logic, digital literacy, and STEM are related.

Multiple information sources require critical reading and logical reasoning. Training programs have been criticized because do not focus on building cognitive skills that enable learners to evaluate, critique, integrate and create new information. The concern is that learners will not be prepared to think critically, to bring on change or to care about how to apply technologies in new, innovative and responsible behaviors (Unesco, 2016). The digital literacy course in this study aimed to address those issues. It was created under three fundamental axes: $\left(1^{\text {st }}\right)$ Digital Technology, $\left(2^{\text {nd }}\right)$ Computational thinking, and $\left(3^{\text {rd }}\right)$ Digital culture. $\left(1^{\text {st }}\right)$ Digital Technology is about physical and virtual components that enable information to be encoded, organized, and retrieved when necessary. It includes a) data representation, b) hardware and software, c) communication and networks; $\left(2^{\text {nd }}\right)$ Computational thinking is the ability to systematize, represent, analyze and solve problems, including a) abstraction, b) algorithm, c) decomposition, and d) pattern recognition. $\left(3^{\text {rd }}\right)$ Digital culture regards interdisciplinary relations of computing with other areas of knowledge, seeking to promote fluency in the use of computational knowledge to express solutions and cultural manifestations in a contextualized and critical way. The digital culture involves a) technology and society, b) digital citizenship, and c) digital comprehension (Raabe et al., 2018). Based on these axes, the themes of the classes in the digital literacy course were planned.

\section{Methodology}

The general objective of the educational experience reported herein was to enable students from a rural area become digitally literate. A short course was developed based on the reality of a digitally excluded region. The viability of the course was measured through a test before and after classes, an observational test during the course activities and questionnaires with the participants. We hope that this experience works as a pilot and that improved versions of it would be suitable in other digitally excluded regions. 


\subsection{Design}

This study consisted of two groups: intervention and control. In the intervention group, students participated in the digital literacy course. No student in the control group participated in the digital literacy course. Both took the logic assessment test on the same date (in the months of July and December 2019), before and after the course period which occurred between August to November of 2019, every 2 weeks. Observational scales were performed during the classes. Questionnaires for legal guardians, students, and teachers were applied. We elaborated on these instruments for this study - their concepts and how they were constructed are further discussed.

The digital literacy course was held for a total of $16 \mathrm{~h}$, divided into 8 classes of $2 \mathrm{~h}$ each. During each class, a researcher introduced the content and explained the activity of the day, with an approximate duration of $30 \mathrm{~min}$. During the students' performance of activities (approximately $90 \mathrm{~min}$ ), this same researcher was responsible for interacting with students and helping them with their doubts and demands, with the support of the class teacher. During the activities execution, three observers rotated every 15 min to complete the rating scales (Supplementary Methods 2) for each student participating in the study.

The starting point of this study was the recovery of donated computers from OCS project discussed previously. Twenty-one devices were completely repaired. Those computers were used in this work and then, in the end of the intervention, were donated to the intervention school. The course was organized using applications in the OCS devices, except one class of computational thinking (Supplementary Methods 1.4. Introduction to Programming Logic).

The digital literacy course drew upon the theoretical framework of Brazil's National Common Curricular Base (BNCC) (Brazilian Ministry of Education, 2018), including the content applied to the 5th graders. We designed the course in three sections: (1st) Digital Technology, (2nd) Computational thinking, and (3rd) Digital culture (Raabe et al., 2018).

For the 1st section, we explored math themes: geometric shapes, three-dimensionality, problematization, and balance. For the 2nd section, we approached data visualization and introduction to programming logic. In the 3rd section, we encouraged the students (1) to produce media content, (2) to reflect on their actions in the digital environment, and (3) to be aware of changes in society due to digital technologies. The complete overview of the course is in Fig. 1 and all the detailed information of these classes is available in the Supplementary Methods 1.

\subsection{Participants}

For the intervention group, there were 20 participants (students) in 5th-grade, aged $10-14$ years $(\bar{x}=10.84, S D=0.89)$, from Pureza, Rio Grande do Norte, northeast Brazil. Data from all subjects were collected, although there was one withdrawal during the intervention. Twelve of the 20 participants were female $(60.0 \%)$. For the control group, there were 23 5th-grade students, aged 9-13 years $(\bar{x}=10.78$, 


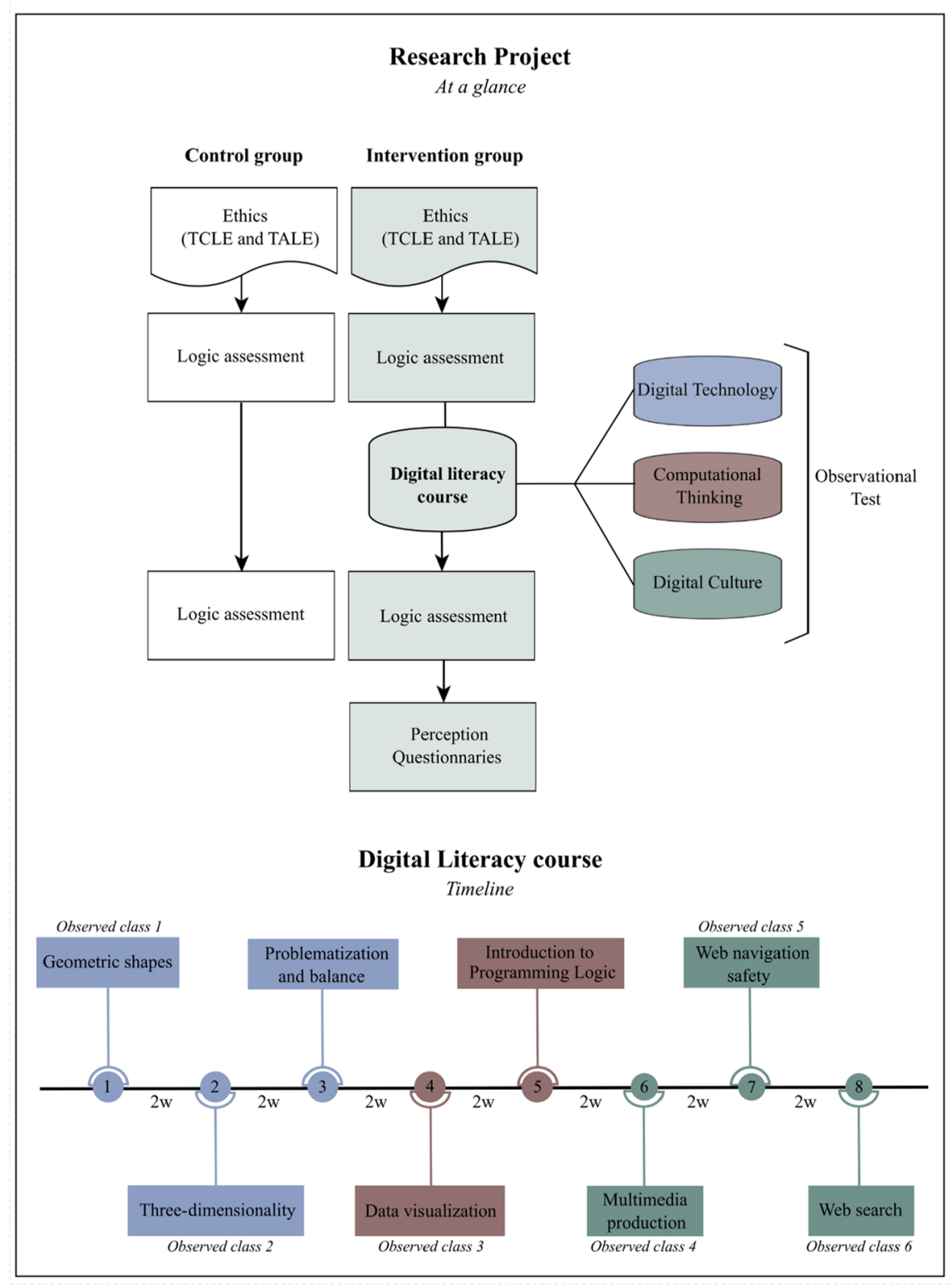

Fig. 1 - The research project structure, and content, and timeline of the Digital Literacy Course. TCLE means Informed Consent Form (for legal guardians of students) and TALE means Informed Assent Form (for minors); Observed class means the activity was part of the observational class (in triplicate) for the scales of confidence in the digital environment and computer interaction; $2 \mathrm{w}$ means that it had 2 weeks' interval from each of the classes; All lesson plans for the digital literacy course, questionnaires, and logic assessment are available in the Supplementary Material 
$\mathrm{SD}=1.12$ ), from a nearby Municipal School. Sixteen of these 23 participants were female $(69.56 \%)$. All their sociodemographic features are available in the Supplementary Table 1 . The intervention school was chosen due to the previous existence of a university reach-out program led by our research group. Non-probability sampling was used, for convenience. All the 5th-graders in the intervention and control school were included. Control school was selected due to its location, with students with similar backgrounds. The distance between the intervention and control schools is $1.38 \mathrm{~km}$; both schools are public.

\subsection{Control and intervention group's logic assessment}

The logic assessment consisted of 8 questions (Supplementary Methods 4). Focused on mathematical logic, the questions were taken from the Mathematics Reference Matrix of the Basic Education Assessment System (SAEB), specifically using the descriptors for the 5th-grade of Elementary Education (Brazilian National Institute of Educational Studies, 2019). We designed the logic assessment due to the absence of validated tests that fit the proposal of this intervention.

The test was performed over an average of $15 \mathrm{~min}$, before and after the course. It was carried out at the same period in both schools, in a paper-and-pencil approach. The reason of this approach was the impossibility of setting up a structure with appropriate devices in the control school, and the non-familiarity of students with the digital medium.

The same questions were used for logic assessment in the pre and post-test. To minimize the repeated testing threat the questions were not discussed with students in the pretest. In the post-test, questions were reordered. The control group was useful to measure the learning effects by repeated exposure.

The tests were corrected and the results were organized in a spreadsheet with raw scores (Supplementary Table 1). The questions were multiple choice and each correct answer was equivalent to 1 score. A score of 8 would be to get all the questions right. The average of scores in each point (pre and post-test for the groups) was used in a multivariate analysis of variance, to answer the question: Do differences exist in the average scores of students' logic pre and post-test between the intervention and control groups? The null hypothesis is "H0 No differences exist in the average scores of students' logic pre and post-test between the intervention and control groups." and the alternative hypothesis is "H1 Differences exist in the average scores of students' logic pre and post-test between the intervention and control groups." More detailed information about this test is discussed in the statistical analysis section.

The SAEB descriptors are divided into the sections: (S1) Space and Form, (S2) Quantities and Measures, (S3) Numbers and Operations/Algebra and Functions, (S4) Information Treatment. They were selected due to the class themes approached in the digital literacy course curriculum. The relationship of descriptors, themes of the classes, and questions in the logic assessment are in Supplementary Table 2.

The 8 questions aimed to address the concepts as detailed. Question 1 aimed to recognize the decomposition of natural numbers in their different orders (Descriptor 15: D15, into S3), and also required photo-visual skills which are included in 
the concept of digital literacy (Eshet-Alkali \& Amichai-Hamburger, 2004)). Question 2 aimed to read information and data presented in tables (D27, into S4) and then establish relationships between units of time (D8, into S2). Question 3 focused on the identification of the location/movement of objects in graphic representations (D1, into S1). Question 4 aimed to recognize the conservation or modification of measurements on the sides, perimeter, area in enlargement and/or reduction of polygonal figures using checkered meshes (D5, into S1). Question 5 focused on the identification of common properties and differences between two-dimensional figures by the number of sides, or by the types of angles (D3, into S1) and also aimed to solve a problem involving the calculation or estimation of areas of flat figures, drawn in checkered meshes (D12, into S2). Question 6 aimed to solve significant problems using standard units of measurement such as $\mathrm{km} / \mathrm{m} / \mathrm{cm} / \mathrm{mm}, \mathrm{kg} / \mathrm{g} / \mathrm{mg}, 1 / \mathrm{ml}$ (D7, into S2). Questions 7 and 8 are based on logical thinking.

\subsection{Students assessment during classes: Observational scales}

The digital literacy course was divided into 8 classes, 6 of which had the observational test (timeline in Fig. 1 shows which classes). There were two subjective scales, ranked from 1 to 10 , where 1 is underperforming and 10 high performing.

There is solid evidence that provides support for perceived usefulness and ease of use as key determinants of digital behavior and technology acceptance-being possible to measure them by psychometric scales (Davis, 1989). Our instruments were also rooted in the self-efficacy theory, defined as "the beliefs in one's capabilities to organize and execute the courses of action required to manage prospective situation" (Bandura, 1977). The scales were developed considering a highly digitally excluded region, in which students did not have access to computers before our course. The first scale is for evaluating the activities developed in the digital environment ( 9 questions). The second scale is for assessing the ability to use digital devices (8 questions). Rating scales are in Supplementary Methods 2.

During each class, the research group consisted of 3 observers and 1 researcher. Observers were extensively trained and were instructed not to interact with students during classes. During the students'performance of activities (approximately $90 \mathrm{~min}$ after the class introduction of $30 \mathrm{~min}$ ), the researcher was responsible for interacting with students and helping them with their doubts and demands (supported by the class teacher). During the activities execution, the 3 observers rotated every $15 \mathrm{~min}$ to complete the rating scales for each student participating in the study.

Observational data included 6 points of observations for each student, for these 2 different scales. Scales questions that could be assessed that day were discussed before the observational test. When a question did not apply to a specific class, the protocol was to withdraw in a previous agreement between the researchers, and it was excluded from the analysis. To assess the reliability of the observational test, we used the intraclass correlation coefficient (ICC), which is best discussed in the statistics section. The longitudinal performance helped us to understand students' progress profiles through a cluster analysis, also discussed in the statistics section. 


\subsection{Perception questionnaires}

Due to the specific characteristics of the digitally excluded region in which this work was carried on, we designed questionnaires for the students, legal guardians, and teachers would be able to give feedback and extra class information. For example, sociodemographic characteristics of the students' families, the student's academic performance, and their levels of contact with the digital environment were collected. Questions were thought to pursue possible differences between students' intragroup performance throughout the course. All questionnaires were carried out after the end of the digital literacy course. The reliability coefficient (Cronbach's Alpha) was applied, and it is further discussed in the statistics section.

The students' legal guardians were invited to a meeting with researchers and to fill in the questionnaire. Those who were not literate were helped to fill in the questionnaire by our team. The objective was to investigate the digital culture at home as it could influence student's learning. The key issues assessed were whether students had access to digital devices at home, their household income, and the familiarity of their legal guardians with computers. The complete questionnaire is available at Supplementary Method 3.3. Data from legal guardian and students questionnaires' were used to check dependency relationships between students' longitudinal performance.

For the student questionnaire, issues such as their access to computers at home, difficulties during digital literacy classes, and their shyness to ask for help during class were addressed. They were asked to complete the questionnaires themselves with a chance to answer questions at any time. The complete students' questionnaire is available in Supplementary Methods 3.2.

In the teachers 'questionnaire, the questions were directed to know the students' performance beyond the classes of the digital literacy course. That is, how the students were behaving and reacting as a result of the classes. The main teacher of the class, the coordinator, and the school principal were asked to answer the questionnaire during a school meeting. The complete teacher' questionnaire is available in Supplementary Methods 3.1.

\subsection{Ethical considerations}

This study adhered to the norms and guidelines proposed by resolution $466 / 12$ of the National Health Council, which regulates research involving humans. The project proposal was approved through the Federal University of Rio Grande do Norte's ethical committee (CAAE: 83,319,618.5.0000.5537). Participants and their legal guardians were informed about the purpose and all the steps of this study and consent was obtained for experimentation. School names were suppressed for to avoid students' identification. 


\subsection{Statistical analysis}

All statistical analysis was performed using $\mathrm{R}$ 3.6.2.

\subsubsection{Logic assessment}

MANOVA-Multivariate analysis of variance-is a robust analysis of longitudinal and multivariate data in factorial experiments. MANOVA was carried out to evaluate the significance of differences between pre and post-test of logic assessment, for intervention and control groups. It can be used to quantify the amount of variability associated with the level and pattern effects or, as here, between groups (control and intervention) and time (pre and post-test). It is a Profile Analysis by Group, that needs testing Parallelism (Ho: Profiles are parallel, this step uses the Wilks statistics), Equal Levels (Ho: Profiles have equal levels), and Flatness (Ho: Profiles are flat). When profiles are not parallel and not coincident, it allows a comparison of each class through ANOVA One-Way and Tukey HSD tests. The profileR package was used to measure all these steps (Desjardins, 2020). To test the reliability of this instrument, it was used the Cronbach's Alpha Based on Standardized Items (Cronbach, 1951) with $N=8$ (number of questions in the logic assessment) and $\mathrm{N}$ of Items $=19$ for intervention and 23 for control groups, where above 0.80 minimal level recommended for basic research.

\subsubsection{Observational testing}

For inter-rater reliability, the intraclass correlation coefficient (ICC) was tested to estimate possible bias between the scores from the three observers at six points (the observed classes) — using the irr package (Gamer et al., 2010) with one way model (Shrout \& Fleiss, 1979). The exclusion criterion for longitudinal data (6 classes observed) was more than two absences. With up to two absences, an estimate was made by interpolation of means. Cluster analysis was performed to assess possible similarities between student profiles through hclust function from cluster package (Maechler \& Rousseeuw, 2019). The difference between groups found in cluster analysis was estimated using MANOVA -Profile Analysis by Group: Testing Parallelism, Equal Levels, and Flatness_profileR package (Desjardins, 2020). In this analysis, due to the failure of the parallelism hypothesis, the TukeyHSD test was used for each class of multiple means comparison between groups.

\subsubsection{Questionnaires}

The longitudinal progress data of students during the course can be classified into 3 subgroups. To assess whether any sociodemographic or exposure factors to the extra-class digital environment were influencing the difference between the groups, Pearson chi-squared test was performed. To measure the reliability of the questionnaires, it was used Cronbach's Alpha Based on Standardized Items 
(Cronbach, 1951) with $N=10$ and 16 (legal guardians and students, respectively) and $\mathrm{N}$ of Items $=19$ for both students and their legal guardians. Cronbach above 0.80 is the minimal level recommended for basic research.

We considered significant the comparisons with $P$-value $<0.05$. Std Err means the standard deviation of its sampling distribution.

\section{Results}

The 5th-grade students from the intervention group were invited to attend digital literacy classes during the second semester of 2019. The classes were taught using devices from the OCS project, with a logic assessment applied before and after classes. During the course activities, students were observed regarding the confidence in the digital environment and the interaction with the computer itself. Great optimism and adherence from students in the activities were observed. Students were committed to the steps and goals of digital activities, and they usually did not want to leave after class time was up.

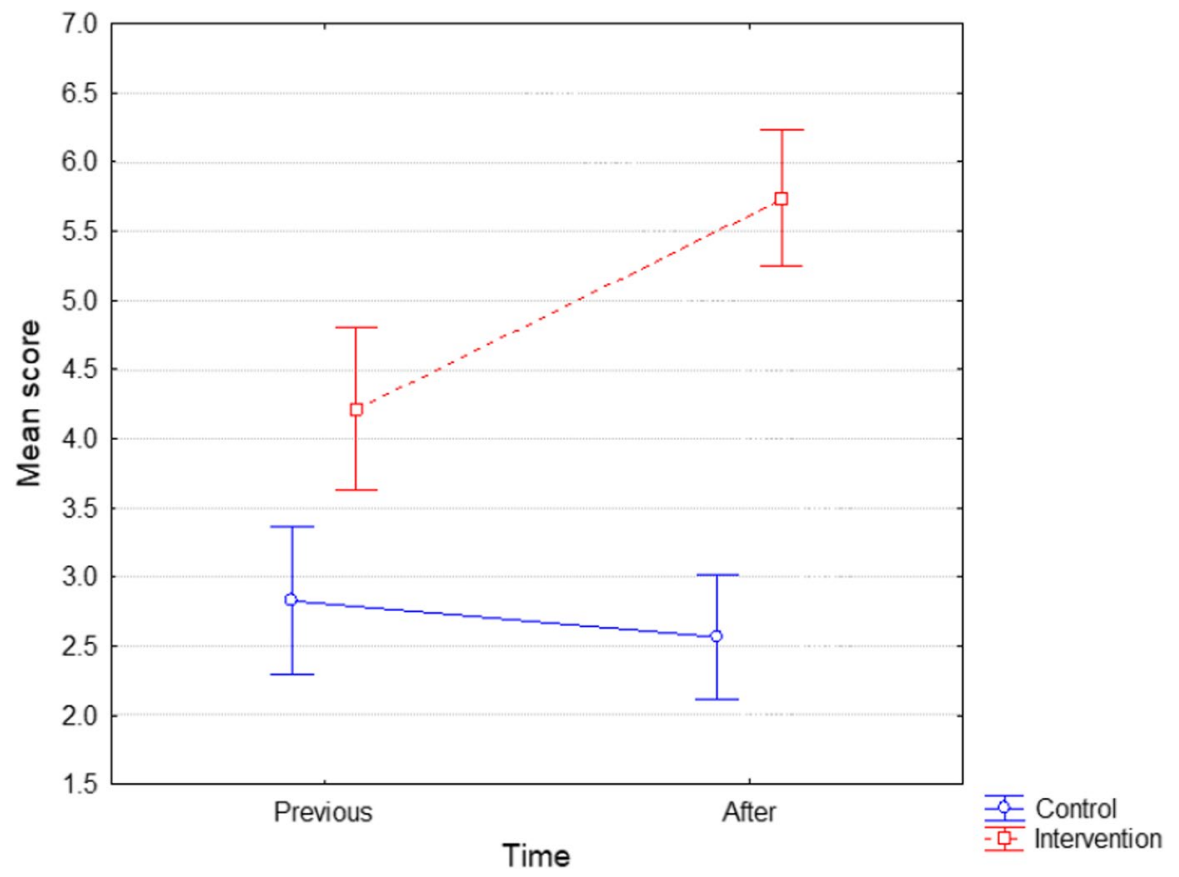

Fig. 2 - Logic assessment scores previously and after the intervention, applied to the 5th-grade students. The evaluation was carried out twice in the same period for the groups: (1) Intervention, that took the digital literacy course and (2) Control, that did not take the digital literacy course. Mean score means the average of the students' logic assessment scores. Individual scores are available in Supplementary Table 2 


\subsection{Students improved in logic assessment after the digital literacy course}

The students' logic assessment for the intervention and control groups were evaluated to verify the effect of the digital literacy course. The intervention effect was tested by comparing the performance of the intervention group versus the control (Fig. 2). The MANOVA test rejected parallelism $(p=0.0014)$. Then, an ANOVA was performed at each point ("previous" and "after") separately, with a focus on the inter-group performance. There were significant differences in students' logic assessment performance between the two groups before any intervention by this work $(p=0.0011)$. After the intervention, significant differences in students' logic assessment performance between the two groups remained $(p<0.0001)$.

For the intervention group, considering the intra-group difference (points "previous" and "after"), an ANOVA revealed that the Digital literacy course intervention positively affected the students' performance in logic assessment $(p=0.0198)$. The difference between previous and after assessment in the control group was not statistically significant.

The intervention group logic assessment mean score was 4.2105 (Std. Err. 0.2912 ) previously and 5.7368 (Std. Err. 0.2442) after the digital literacy course. For the control group, the mean score of logic assessment was 2.8260 (Std. Err. 0.2647) and 2.5652 (Std. Err. 0.2219). The grade for all tests, per student, is available in Supplementary Table 2.

In regards to the logic assessment as an instrument, it had an acceptable reliability coefficient. The overall Cronbach's Alpha was 0.829. Separately, the intervention pre-test had the Cronbach's Alpha of 0.951, and the post-test had one of 0.991. The control pre-test had Cronbach's Alpha of 0.865, and the post-test had one of 0.800 .

\subsection{There are 3 groups of students regarding performance during the course time}

Intraclass correlation coefficient for the Confidence scale showed that there was a significant reliability between observers $(\mathrm{F}(1283,2568)=4.33, p$-value $<0.0001)$. The Interaction scale also had a significant reliability $(\mathrm{F}(1282,2566)=4.33$, $p$-value $<0.0001)$. For both scales, ICC $=0.526$ was observed, with confidence interval of $0.495<$ ICC $<0.557$. Since there was significant reliability between observers on both scales, we proceeded to search for differences between students observed during the course.

There was an excessive amount of absences throughout the semester. For the cluster analysis, students with more than 2 absences were removed (totaling 5 students), making the final sample of this analysis $n=14$. It is possible to observe 3 groups according to hierarchical clustering, both for the Confidence Scale and for the Interaction Scale (Fig. 3).

For the Confidence Scale a MANOVA was performed (Fig. 4) to assess the difference between groups identified by the cluster analysis with the classification factor being the clusters, the evaluation factor being time (class) and as response 


\section{Self-confidence in the digital environment}

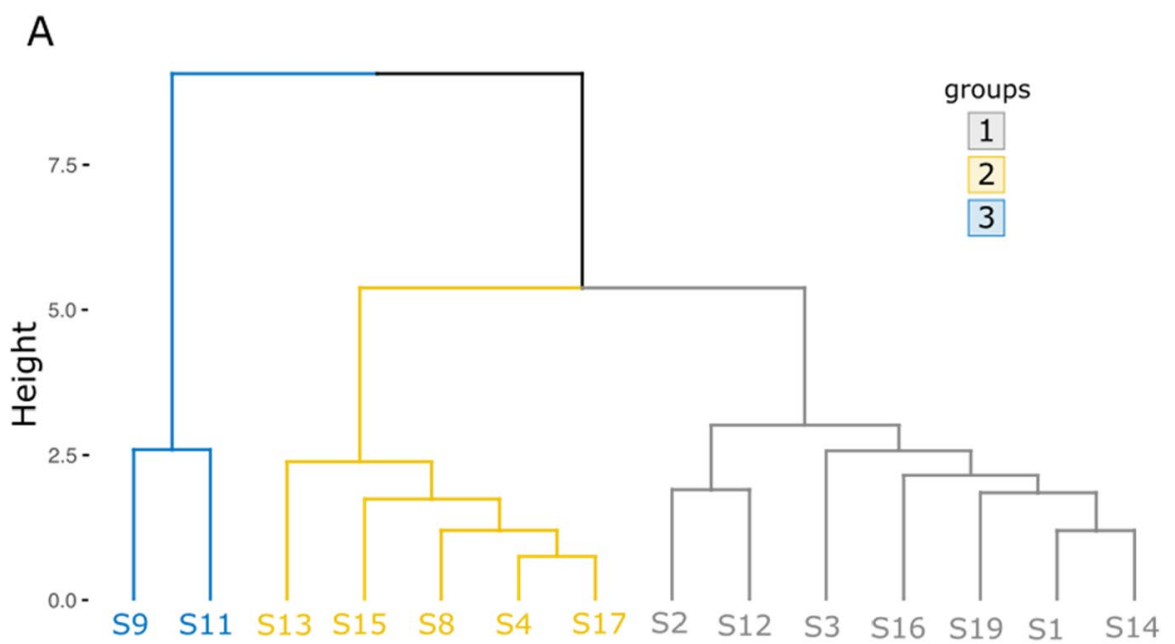

B

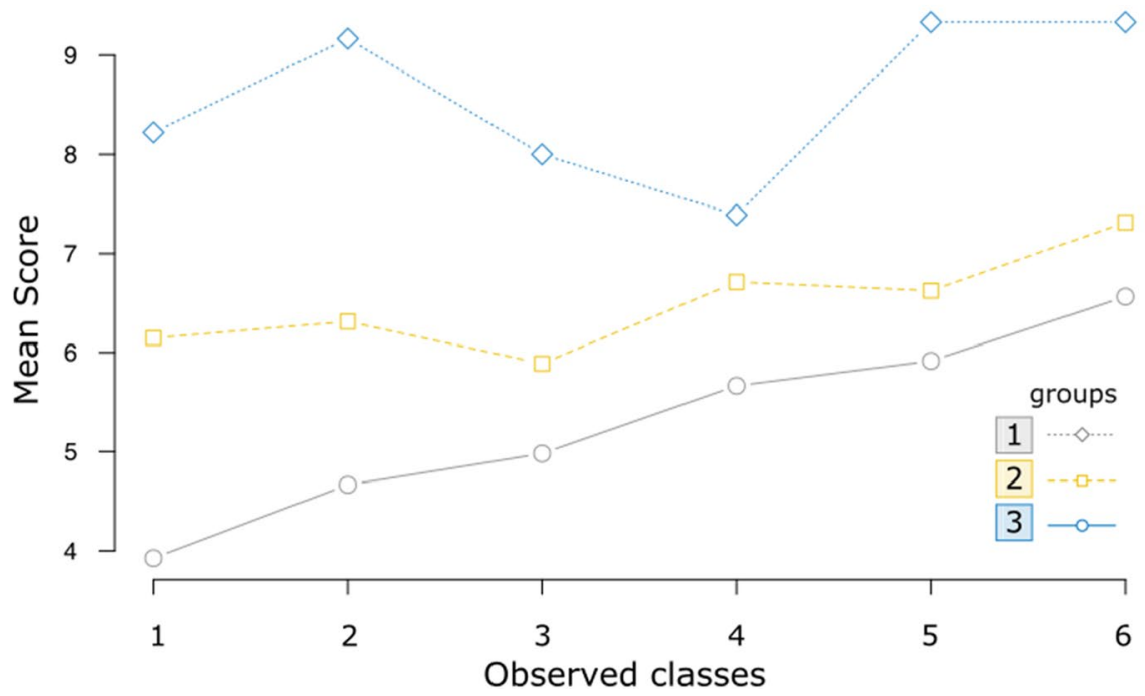

Fig. 3 - Clustering of student scores in the observational test, characterizing their performance during the time of the digital literacy course. 3A represents the groups separated by scores from the scale of confidence in the digital environment. 3B is the mean score of students during the digital literacy course. The lines represent the groups found in the cluster analysis (for the scale of confidence in the digital environment)

variable the mean score. The MANOVA test rejected parallelism (Wilks statistics $(10,14)=0.1043, p$-value $=0.0325)$, and Equal Levels $(F(1,2)=58.8$, $p$-value $<0.0001)$, indicating a significant effect of the Clusters classification factor, 
A

\section{Computer interaction}

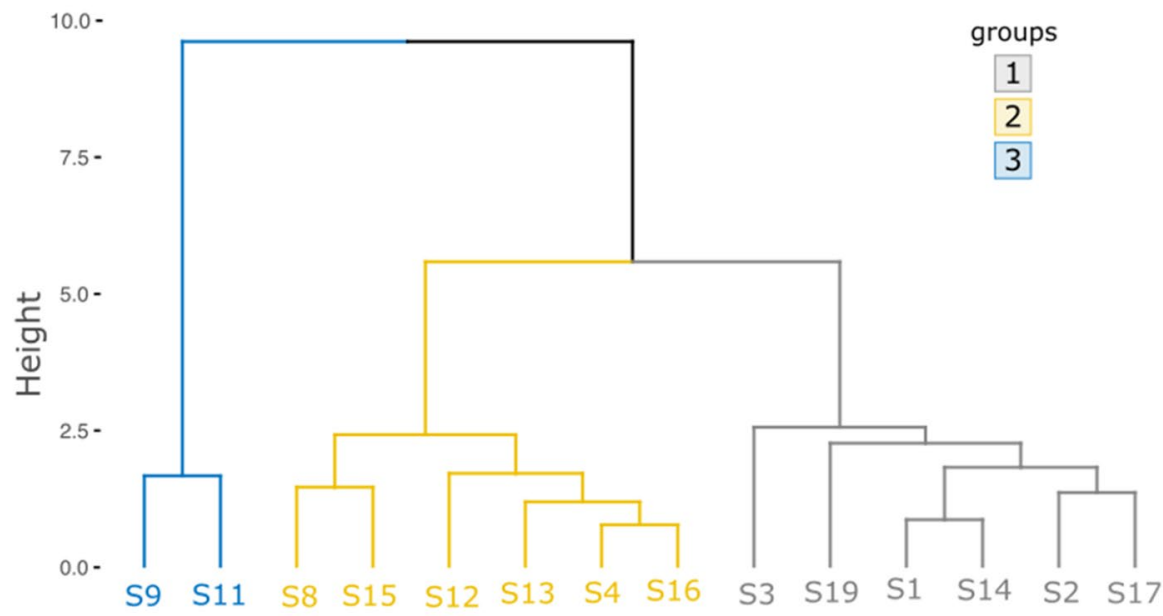

B

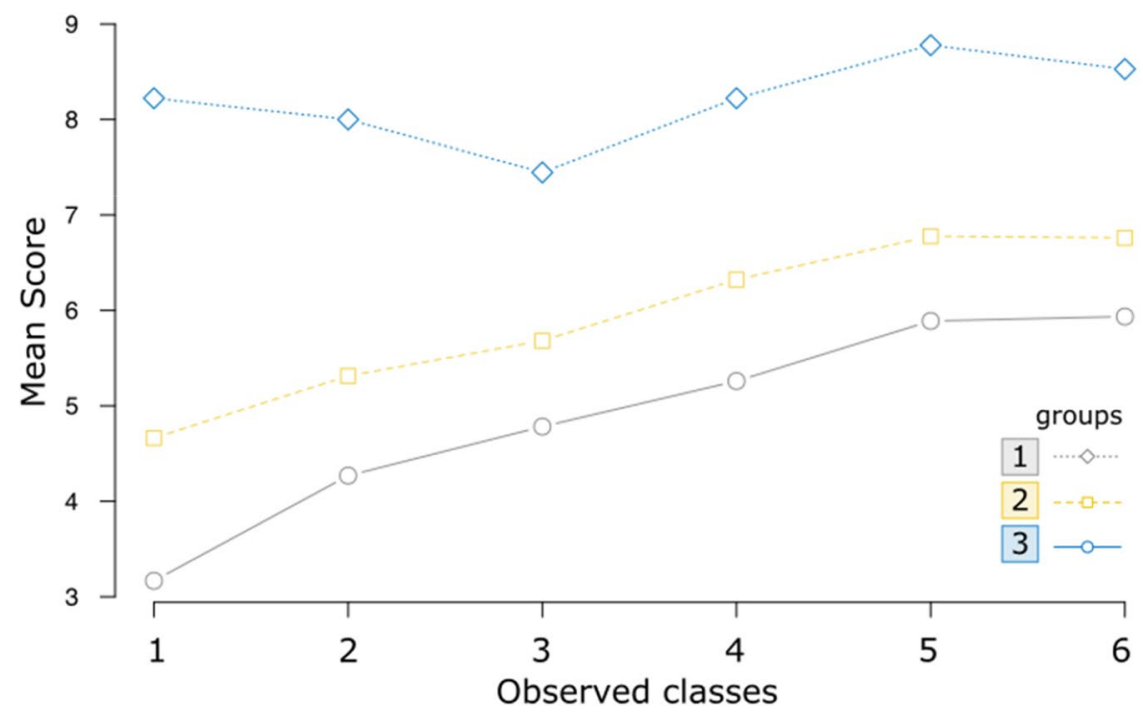

Fig. 4 - Clustering of student scores in the observational test, characterizing their performance during the time of the digital literacy course. 3A represents the groups separated by scores from the scale of computer interaction. 3B is the mean score of students during the digital literacy course. The lines represent the groups found in the cluster analysis (for the scale of computer interaction)

which allowed a comparison of these in each class through ANOVA One-Way and Tukey HSD tests (Fig. 4 and Table1).

For the Interaction Scale, using the same parameters, there was no association between the clusters and time; in other words, the MANOVA test accepted 
Table 1 Comparison between the groups found in the cluster analysis, per class. Bold entries on the " $p$-value adj" column indicate statistical significance (adjusted p-value $<0.05$ ).

\begin{tabular}{|c|c|c|c|c|c|c|}
\hline & \multicolumn{3}{|c|}{ Confidence in the digital environment } & \multicolumn{3}{|c|}{ Computer interaction } \\
\hline & Groups & $\begin{array}{l}\text { Diff. inter- } \\
\text { groups (mean) }\end{array}$ & $p$-value adj * & Groups & $\begin{array}{l}\text { Diff. inter- } \\
\text { groups (mean) }\end{array}$ & $p$-value adj $*$ \\
\hline \multirow[t]{3}{*}{ Class 1} & $2-1$ & 2.2222 & 0.0016 & $2-1$ & 1.4962 & 0.0308 \\
\hline & $3-1$ & 4.2962 & 0.0001 & $3-1$ & 5.0555 & $<0.0001$ \\
\hline & $3-2$ & 2.0740 & 0.0248 & $3-2$ & 3.5592 & 0.0010 \\
\hline \multirow[t]{3}{*}{ Class 2} & $2-1$ & 1.6481 & 0.0412 & $2-1$ & 1.0444 & 0.0328 \\
\hline & $3-1$ & 4.5000 & 0.0005 & $3-1$ & 3.7314 & $<0.0001$ \\
\hline & $3-2$ & 2.8518 & 0.0139 & $3-2$ & 2.6870 & 0.0006 \\
\hline \multirow[t]{3}{*}{ Class 3} & $2-1$ & 9.074 & $\mathbf{0 . 0 3 0 0}$ & $2-1$ & 8.992 & 0.1508 \\
\hline & $3-1$ & 3.0185 & $<0.0001$ & $3-1$ & 2.6620 & 0.0035 \\
\hline & $3-2$ & 2.1111 & 0.0011 & $3-2$ & 1.7628 & 0.0411 \\
\hline \multirow[t]{3}{*}{ Class 4} & $2-1$ & 1.0462 & 0.1562 & $2-1$ & 1.0628 & 0.0485 \\
\hline & $3-1$ & 1.7222 & 0.0920 & $3-1$ & 2.9629 & 0.0006 \\
\hline & $3-2$ & 6.759 & 0.6411 & $3-2$ & 1.9001 & 0.0141 \\
\hline \multirow[t]{3}{*}{ Class 5} & $2-1$ & 7.083 & 0.1144 & $2-1$ & 8.875 & 0.0985 \\
\hline & $3-1$ & 3.4166 & $<0.0001$ & $3-1$ & 2.8888 & 0.0006 \\
\hline & $3-2$ & 2.7083 & 0.0002 & $3-2$ & 2.2013 & 0.0096 \\
\hline \multirow[t]{3}{*}{ Class 6} & $2-1$ & 7.500 & 0.2334 & $2-1$ & 8.240 & 0.1217 \\
\hline & $3-1$ & 2.7685 & 0.0021 & $3-1$ & 2.5925 & 0.0014 \\
\hline & $3-2$ & 2.0185 & 0.0173 & $3-2$ & 1.7685 & 0.0183 \\
\hline
\end{tabular}

*TukeyHSD test

parallelism (Wilks statistics $(10,14)=0.3416, p$-value $=0.4899)$. Then, Equal Levels hypothesis was rejected, as $\mathrm{F}(1,2)=36.98$, $p$-value $<0.0001$, meaning that the groups were significantly different over the intervention time. MANOVA rejected Flatness for the effect of time $(F(5,7)=13.4468, p$-value $=0.0018)$, meaning the students were learning over time as the profiles were not flat across classes; on the contrary, they were ascendants (Fig. 3 and Table 1).

There was a significant difference among all groups in class 1 , which points to a previous difference of knowledge among the groups (Table 1). For class 2 there was also a significant difference among all groups. In class 3, groups 1 and 2 were not statistically different on the Interaction Scale. In class 4, no group was significantly different on the Confidence Scale. In both classes 5 and 6, the groups 1 and 2 were not statistically different, showing a similarity between them.

We hypothesized that the observed performance difference could be due to different sociodemographic features such as family contexts and digital stimuli. So, we tested the association between the groups and the answers to the questionnaires for both legal guardians and students, such as access to the computer, family income, the familiarity of the guardians with the computer or shyness in asking the teacher for help during the class. No statistical significance was found. Some key responses from students are shown in Fig. 5. 


\section{Students questionnaire}

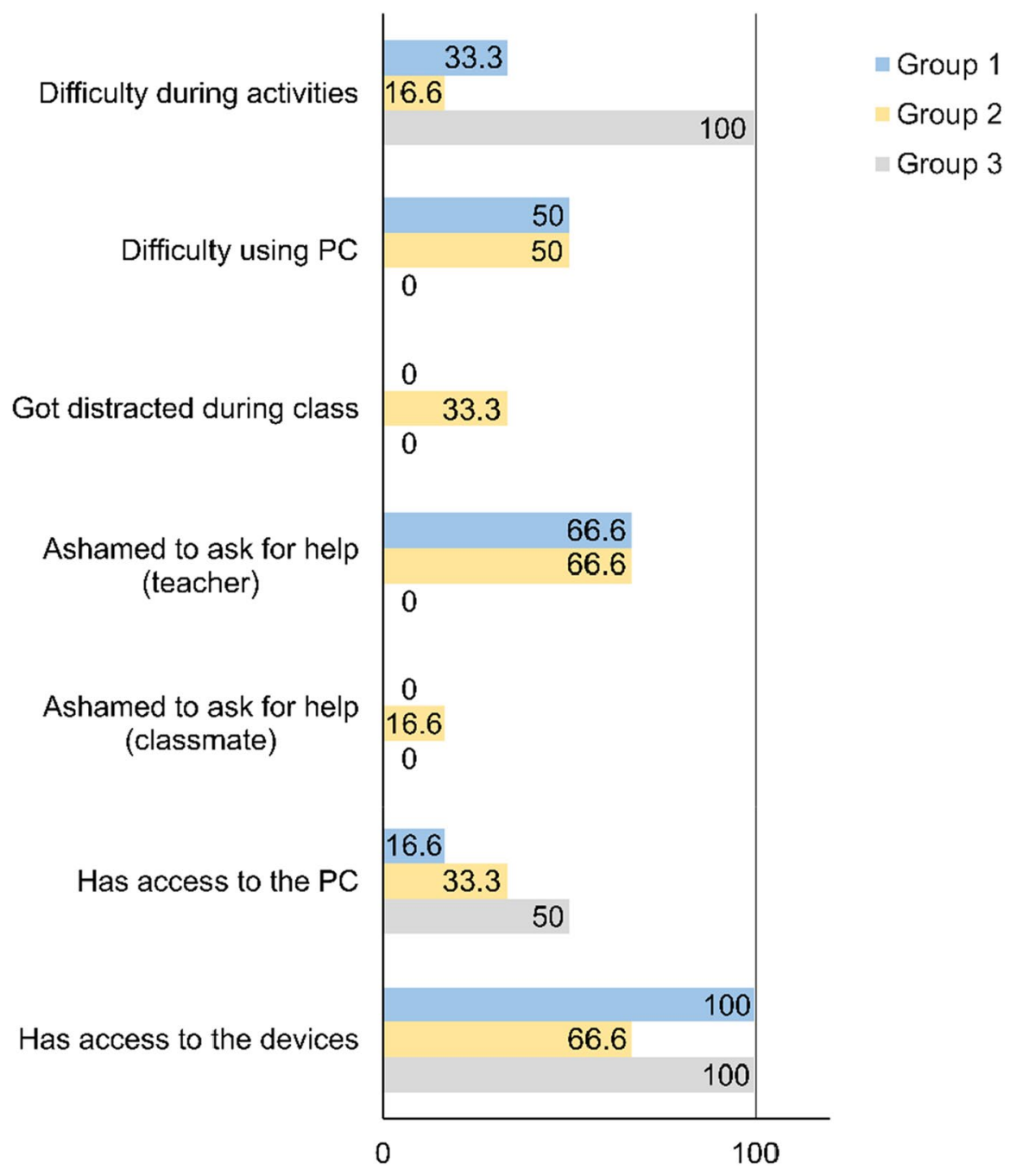

Fig. 5 - Students' answers about the digital literacy course and access to digital devices. The representation is organized by the groups found in the cluster analysis (Groups 1, 2, and 3). The y-axis corresponds to the questions in the students' questionnaire, and the $\mathrm{x}$-axis is the percentage of students who answered "Yes" in each group

The students in group 3, those who performed better during classes, had in common being outgoing and they had the drive to ask for help from teachers or classmates, they were not distracted during class, and all of them had access to digital devices outside classes. They also reported not having difficulty using computer. Meanwhile, students in groups 1 and 2 reported difficulty using the digital device, shyness in asking for help from teachers or classmates. Some 
students from group 2 did not have any kind of access to digital devices in extra class activities.

\subsection{Students, legal guardians, and professors' perception}

Legal guardians were born between 1960-1991, and 16.7\% had no schooling, 50\% studied up to elementary school and $33.3 \%$ finished high school. With respect to income, $41.7 \%$ claimed to have no income and $33.3 \%$ had up to one minimum wage_-998 BRL/Month (about \$189.07). 94.4\% of the families from the intervention group lived in a rural area. In the section for comments, legal guardians often reported that the school transformed their children.

In the digital context, $50 \%$ of the legal guardians answered they had never used a computer, $16.7 \%$ had used, but not often, and $33.3 \%$ used computer frequently. We tested whether the $33.3 \%$ who had used computer frequently were the ones with the highest income and there was a dependency between these variables (Pearson's Chisquared test, $p$-value $=0.0072$ ). $83.3 \%$ of the legal guardians answered that the student had some way to access electronic devices (computers, smartphones or tablets, owned by the legal guardian or by relatives or neighbors). When asked for how long the student used a device in a day, $55.6 \%$ answered that up to $1 \mathrm{~h}, 16.7 \%$ up to $2 \mathrm{~h}$, $11.1 \%$ up to 3 h. $16.6 \%$ did not use it.

About $64.4 \%$ of students marked that they could concentrate in the digital environment, and $31.6 \%$ got distracted using the computer. $52.6 \%$ answered that they faced difficulty in using the computer, and 52\% were ashamed to ask the teacher for help. $94.7 \%$ said they asked for help for the classmates without shame. All of them said they had fun in the digital classes and that they used what they learned in other moments. All of them liked how the classes were conducted and that the teacher helped in the assignments. $94.7 \%$ said they liked to use the computer in the classroom. $73.7 \%$ of the students answered that they have access to electronic devices, diverging from the $83.3 \%$ found in the legal guardians' response.

In regards to the questionnaires as instruments, they had an acceptable reliability coefficient. The Cronbach's Alpha was 0.972 for the students' legal guardians and 0.937 for the students' questionnaire.

All teachers agreed that students found the subjects interesting, demonstrated more creativity and that the use of devices in the classroom generated useful results. All teachers claimed that students' achievement was greater in classes with digital devices. 


\section{Discussion}

\subsection{Students improved greatly throughout the digital literacy course}

\subsubsection{Logic assessment}

The students' progress was astonishing. The ones who did not know how to use the mouse touchpad were able to develop complex activities, such as the authorial production of multimedia. The logic assessment included questions of spatial, visual, and numerical logic (Supplementary Table 2) which were addressed during the digital literacy course. Overall, the assessment presented a good reliability coefficient, being great when data of intervention school was treated separately. In the pre-test, there was already a difference in the scores of intervention and control groups, even though both of them are from public schools in close proximity, about $1.3 \mathrm{~km}$ apart. One of the reasons that might have influenced this initial difference was a prior 3-year project in the intervention school, which aimed to improve the quality of teaching and also improved the school infrastructure (unpublished results).

The Digital Literacy Course improved the students' scores in the logic assessment. There was a statistically significant difference between scores of pre and post-test in the intervention, but not in the control group. This data provides evidence that $16 \mathrm{~h}$ of digital course focused on the development of logic skills can be effective in a digitally excluded region. A rural area initiative of a digital literacy framework with practical content for indigenous people was successful in India (Nedungadi et al., 2018). It demonstrates the potential value of an adequate Digital Literacy Course as a powerful lever for Digital Inclusion. However, our study was conducted in only one location. To validate the approach and instruments, we encourage it to be carried out in other locations with similar characteristics.

Our sample consisted of all students in the 5th-grade for the intervention group and all for the control group. The reality of Brazilian education in underprivileged areas is a high rate of school retention (Carvalho \& Firpo, 2014). Thus, there was $5.26 \%$ outside of the expected age in the intervention group and $26.08 \%$ in the control group. There is a possibility of bias due to age and cognitive development (Micklewright et al., 2012). However, we decided to keep the entire sample due to the study being designed for regions where this often happens. In addition, these students were not responsible for changing the pattern found in the tests performed.

\subsubsection{Observational testing}

During the 14 weeks of course, a high agreement on student performance between the Confidence and Interaction scales was observed. It was possible to identify 3 profiles of students' longitudinal performance in the course: Group 1 showed lower scores since the first class in both Confidence and Interaction 
scales. Group 2 showed middle scores. For both groups 1 and 2, scores progressively increased over the course. Group 3 presented higher scores since the beginning and remained with high and close scores during all the classes. In the first class of the course, a significant difference among all groups was observed which points to a previous difference of knowledge among the groups. In the 4th class, there was not a significant difference in the Confidence Scale among groups. This class was one of the most challenging in the course (Fig. 1) due to the activity performed: a combination of text, images, memes, GIF's to communicate a synthesis of content that students had already studied throughout the semester. In the 5th and 6th classes, groups 1 and 2 were not statistically different, showing a similarity between them.

Then, we tested if the observed difference among groups could be due to different sociodemographic features. However, no statistical significance was found for an association between the groups and the following features: access to the computer; family income; familiarity of legal guardians with computers; and being ashamed of asking the teacher for help during class. Certainly, the sample size of the groups influenced this outcome, especially for group 3 that had only two students. The number of absences during digital literacy classes was high, which led us to exclude some of the students from the clustering.

Group 3, which had the highest scores on both Confidence and Interaction Scales, reported absence of difficulty using the computer but having difficulty during the activities. These students often helped their classmates during classes, helped set up and dismantle the structure for digital classes, and started exploring digital platforms and emails outside the classroom. They did not need help and used to end the activities very fast. The self-reported difficulty during the activities was inconsistent with their performance. A study across four different countries (Brazil, China, Canada, and Italy) indicated that the self-system may be a culture-general as well as a culture-specific phenomenon. Self-perceptions of social competence was positively associated with academic achievement in Canadian and Chinese children, but not in Brazilian and Italian children (Chen et al., 2010). As group 3 demonstrated easy social adaptation, that self-perception may be related to cultural issues. Furthermore, their perceived competence could be related to self-efficacy (Bandura, 1977).

Meantime, students in groups 1 and 2 reported difficulty using the digital device and presence of shyness in asking for help from teachers or classmates. Some students from group 2 did not have any kind of access to digital devices in extra class time. Regardless of little or no prior digital contact before the course, all students progressed on the Observation Scales scores during the course. This indicates that the classes were capable of both establishing an initial base and could assist in the development of the use of devices for learning.

There is a need for measurement methodologies for the digital learning of young students. The scales presented here are initial but deserve attention due to the lack of validated tests. Scales to assess the use of technology are powerful (Davis, 1989; Davis et al., 1989), showing that a good instrument is capable of having a comprehensive impact on society on a global scale. We encourage the scales here presented to be adapted and applied in other locations. 


\subsection{Students, legal guardians, and professors' perceptions}

During the response to the questionnaires, female students commented about being ashamed to ask for help if the teacher was a man. We investigated whether students who were ashamed to ask the teacher for help were sex-related. According to Pearson's Chi-squared test, there was no dependency relationship between shame and sex ( $p$-value $=0.0863$ ). However, it is important to mention that girls, rural students, and children from minority or other socially marginalized groups generally learn less, compared to boys, city children, and other disadvantaged groups (World Bank, 2018).

Approximately $95 \%$ of the families of this study live in a rural area and $50 \%$ of legal guardians have never used a computer in their lives. The Brazilian Northeast has $52.3 \%$ of the population connected to the internet (IBGE, 2019), which is approximately the same proportion we found in this study. Unsurprisingly, those who use the computer frequently are significantly associated $(p$-value $=0.0072$ ) with the highest income. No legal guardian in this study reached higher education (some are illiterate) and most of them have no or less than a minimum wage monthly income. People living in rural areas are more affected by social exclusion parameters such as their incomes, and educational levels-and these social disparities are likely to be a more grave problem than infrastructural needs such as access to the internet (Basu \& Chakraborty, 2011).

Regarding the relationship between early childhood and poverty, the more time in poverty from birth to age 9 , the worse mental health is for these individuals as adults. Mediators presented are the confluence of psychosocial (violence, family turmoil, child separation from family) and physical (noise, crowding, substandard housing) risk factors (Evans \& Cassells, 2014). These risk factors influence academic achievement (Heberle \& Carter, 2020). We observed instability in the performance of some students which may be related to these factors. On the other hand, legal guardians often reported in the comments section of the questionnaire that the school transformed their children.

\subsection{Bottlenecks}

We understand that since this work was longitudinal (one academic semester), some nonspecific problems of the project were noticed. The difficulties faced during this work development were from different natures: (1) — school lack of installations, electrical networks and intermittent electricity; (2)—inappropriate internet connection; (3)-inadequacies in both classroom environment (especially classroom temperature) and storage of equipment; (4) - completely digitally excluded students; (5) - teachers had little familiarity with the digital environment; (6) school attendance was challenging, since children often missed class. Excluding the attendance, those were exactly the same bottlenecks found in previous Brazilian study that used an approach like ours (Andriola \& Gomes, 2017; Nascimento et al., 2011). 


\subsection{How to apply this course in other locations?}

The Digital Literacy Course contained 8 classes of 120 min each with a structure for 25 students. With 20,150.00 BRL (about \$3,803.82) of investment the chance of improving students' skills in logic is high [Course Costs: Professionals $-6,400.00$ BRL (about $\$ 1,208.16)$ । Computers - 13,750.00 BRL (\$2,595.66). Structure at school: Broadband Internet I Suitable router].

Investing in this course can lead to the creation of sufficiently broad competencies to enable students to act effectively in the production of knowledge and services, and to fluently operate the digital means and work tools. The proposal is "learning to learn", to be able to deal positively with the continuous and accelerated transformation of the technological base. This basis can certainly help in the development process of a human being with a view to their individual and social integration, involving human, technical, cognitive, emotional, socio-political, and cultural aspects. A fundamental part of implementing a project like this (or on a larger scale) is to prioritize the training of professionals involved in digital lectures.

\subsection{Final comments}

Here we demonstrate that the Digital Literacy Course positively affected students' scores in the logic assessment. We report our experience of teaching this course at the elementary school level and found that students responded confidently to it and that they improved essential skills for the digital era. The pandemic of COVID-19 and the global health crisis point to these skills being even more important. We presented here two initial scales for observational testing for students who have had little or no access to computers. We tested a digital literacy framework based on logical thinking and math content for the 5th-grade according to the Brazilian curriculum. We present the logic assessment and questionnaires from legal guardians and students with good reliability coefficients. We believe in the potential of this set of tools and approaches to be applied and improved in other areas of digital exclusion. We encourage other researchers that could act in these regions to use them.

Due to the characteristics of this study, limitations needed to be considered. First, the total sample size for this study was 19 students, which is a relatively small number of participants. The groups were given the logic assessment as pretest and posttest over an interval of 3 months. The pretest measure could have had some effect on the posttest measure, resulting in a repeated testing threat. The findings should not be generalized to encompass all processes of digital literacy in Brazilian education or in a transnational perspective due to the regional characteristics, convenience sampling and selection bias. There is a need to replicate the results in different populations, places, and time periods.

In this context, we offer a feasible solution for the digital gap in which those children live and a potential gain of opportunities in their future.

Supplementary Information The online version contains supplementary material available at https://doi. org/10.1007/s10639-021-10711-z. 
Acknowledgements This paper is dedicated to the memory of Professor Jose Wilton de Queiroz who was a great mentor and colleague. We acknowledge Nayde Fonseca, Augusta Cartaxo, Keila Barreto and Beatricia Costa for their time and teaching; Julyana Vilar and Pollyanne Evangelista for brainstorming in the beginning of this work; Margarita Mavromatis and Leonardo Pinheiro for their patience and care with so many travel logistics; Leonidas Silva and Paulo Branco for technical support and computational help; John E. Donelson (University of Iowa) and Patrick Schwartzhoff (College of Medicine, University of Iowa) for the English review; all the schools' teamwork and Pureza/RN municipal government; and especially to our little students for being such exceptional inspiration to all of us.

Funding Federal University of Rio Grande do Norte, UFRN (08/2018) via the extension program "Population empowerment through education".

\section{Declarations}

Ethics approval The work received ethical approval through the Federal University of Rio Grande do Norte's ethical committee (CAAE: 83319618.5.0000.5537).

Conflicts of interest We wish to confirm that there are no conflicts of interest associated with this publication and no influence from the funders of the study.

\section{References}

Andriola, W. B., \& Gomes, C. A. S. (2017). Programa Um Computador Por Aluno (PROUCA): Uma análise bibliométrica. Educar Em Revista, 63, 267-288. https://doi.org/10.1590/0104-4060.48230

Bezerra, M. E. G., Kassouf, A. L., \& Arends-kuenning, M. (2009). The Impact of Child Labor and School Quality on Academic Achievement in Brazil. IZA: Discussion Papers Series. http://ftp.iza. org/dp4062.pdf

Bakker, A., \& Wagner, D. (2020). Pandemic: Lessons for today and tomorrow? Educational Studies in Mathematics. https://doi.org/10.1007/s10649-020-09946-3

Bandura, A. (1977). Self-efficacy: Toward a unifying theory of behavioral change. Psychological Review, 84(2), 191-215. https://doi.org/10.1037/0033-295X.84.2.191

Barile, J. P., Donohue, D. K., Anthony, E. R., Baker, A. M., Weaver, S. R., \& Henrich, C. C. (2012). Teacher-student relationship climate and school outcomes: Implications for educational policy initiatives. Journal of Youth and Adolescence, 41(3), 256-267. https://doi.org/10.1007/ s10964-011-9652-8

Basu, P., \& Chakraborty, J. (2011). New technologies, old divides: Linking internet access to social and locational characteristics of US farms. GeoJournal, 76(5), 469-481. https://doi.org/10.1007/ s10708-010-9370-x

Bezerra, D. V. F., Queiroz, J. W., Câmara, V. A. V., Maciel, B. L. L., Nascimento, E. L. T., \& Jerônimo, S. M. B. (2021). Factors Associated with Schistosoma mansoni Infestation in Northeast Brazil: A Need to Revisit Individual and Community Risk Factors. American Journal of Tropical Medicine and Hygiene, 104(4), 1404-1411. https://doi.org/10.4269/ajtmh.19-0513

Brazilian Ministry of Education, Silva, R. S., Prado, H. S. A., \& Smole, K. C. S. (2018). Brazilian Common Curricular Base. http://basenacionalcomum.mec.gov.br/images/BNCC_EI_EF_110518_versa ofinal_site.pdf. Accessed 5 Aug 2020

Brazilian National Institute of Educational Studies. (2019). Saeb Mathematics Reference Matrix. (Research Anísio Teixeira (Ministry of Education), trans.). http://portal.inep.gov.br/educacaobasica/saeb/matrizes-e-escalas. Accessed 6 Aug 2020

Brazilian Ministry of Social Development. (2020). Single Registration of the Municipality Pureza - State Rio Grande do Norte (RN). http://mds.gov.br/bolsafamilia. Accessed 5 Aug 2020

Carvalho, S., \& Firpo, S. (2014). O regime de ciclos de aprendizagem e a heterogeneidade de seus efeitos sobre a proficiência dos alunos. Economia Aplicada, 18(2), 199-214. https://doi.org/10.1590/14138050/ea374 
Cheung, A. C. K., \& Slavin, R. E. (2013). The effectiveness of educational technology applications for enhancing mathematics achievement in K-12 classrooms: A meta-analysis. Educational Research Review, 9, 88-113. https://doi.org/10.1016/j.edurev.2013.01.001

Chen, X., Zappulla, C., Coco, A. L., Schneider, B., Kaspar, V., Oliveira, A. M. D., et al. (2010). Self-perceptions of competence in Brazilian, Canadian, Chinese and Italian children: Relations with social and school adjustment. International Journal of Behavioral Development, 28(2). https://doi.org/10. 1080/01650250344000334

Chowdhry, D. G., Verma, R., Mathur, M., Ghosal, D., \& Sarkar, S. (2020). Digital Workplace: The Human Interface. In The'\&nbsp;' evolution of business in the cyber age: Digital transformation, threats, and security. Oakville, ON, Canada: AAP, Apple Academic Press.

Cronbach, L. J. (1951). Coefficient alpha and the internal structure of tests. Psychometrika, 16(3), 297-334.

Davis, F. D. (1989). Perceived usefulness, perceived ease of use, and user acceptance of information technology. MIS quarterly, 319-340

Davis, F. D., Bagozzi, R. P., \& Warshaw, P. R. (1989). User Acceptance of Computer Technology: A Comparison of Two Theoretical Models. Management Science, 35(8), 982-1003.

Desjardins, C. D. (2020). ProfileR: Profile Analysis of Multivariate Data in R. Computer software, CRAN Repository

Durak, H. Y., \& Saritepeci, M. (2018). Analysis of the relation between computational thinking skills and various variables with the structural equation model. Computers \& Education, 116, 191-202. https://doi.org/10.1016/j.compedu.2017.09.004

Echalar, A. D. L. F., \& Peixoto, J. (2017). Programa Um Computador por Aluno: o acesso às tecnologias digitais como estratégia para a redução das desigualdades sociais. Ensaio: Avaliação e Políticas Públicas em Educação, 25(95), 393-413. https://doi.org/10.1590/s0104-40362017002501155

Erdogdu, F., \& Erdogdu, E. (2015). The impact of access to ICT, student background and school/home environment on academic success of students in Turkey: An international comparative analysis. Computers \& Education, 82, 26-49. https://doi.org/10.1016/j.compedu.2014.10.023

Eshet-Alkali, Y., \& Amichai-Hamburger, Y. (2004). Experiments in digital literacy. Cyberpsychology \& Behavior: The Impact of the Internet, Multimedia and Virtual Reality on Behavior and Society, 7(4), 421-429. https://doi.org/10.1089/cpb.2004.7.421

Evans, G. W., \& Cassells, R. C. (2014). Childhood poverty, cumulative risk exposure, and mental health in emerging adults. Clinical Psychological Science : A Journal of the Association for Psychological Science, 2(3), 287-296. https://doi.org/10.1177/2167702613501496

Flavin, M. (2017). Disruptive technology enhanced learning. Palgrave Macmillan UK. https://doi.org/10. 1057/978-1-137-57284-4

Freeman, J., \& Park, S. (2015). Rural realities. Transforming Government: People, Process and Policy, 9(4), 465-479. https://doi.org/10.1108/TG-03-2015-0012

Gamer, M., Lemon, J., \& Singh, I. (2010). irr: Various Coefficients of Interrater Reliability and Agreement. Computer software, CRAN Repository

Hampden-Thompson, G., \& Galindo, C. (2017). School-family relationships, school satisfaction and the academic achievement of young people. Educational Review, 69(2), 248-265. https://doi.org/10. $1080 / 00131911.2016 .1207613$

Heberle, A. E., \& Carter, A. S. (2020). Young children's stereotype endorsement about people in poverty: Age and economic status effects. Children and Youth Services Review, 108, 104605. https://doi.org/ 10.1016/j.childyouth.2019.104605

Helsper, E. J. (2012). A Corresponding Fields Model for the Links Between Social and Digital Exclusion. Communication Theory, 22(4), 403-426. https://doi.org/10.1111/j.1468-2885.2012.01416.x

Hickey, S., \& Hossain, N. (Eds.). (2019). The politics of education in developing countries: from schooling to learning. Oxford University Press. https://doi.org/10.1093/oso/9780198835684.001.0001

Hill, H. C., Rowan, B., \& Ball, D. L. (2005). Effects of teachers' mathematical knowledge for teaching on student achievement. American Educational Research Journal, 42(2), 371-406. https://doi.org/10. 3102/00028312042002371

Houtenville, A. J. (2007). Parental Effort, School Resources, and Student Achievement. The Journal of human resources.

IBGE. (2019). Sistema de Informações e Indicadores Culturais (Vol. 42) . Estudos e Pesquisas Informação Demográfica e Socioeconômica.

International Telecommunication Union. (2019). Measuring digital development. Genebra, Switzerland 
Johnson, L., Adams Becker, S., Estrada, V., \& Freeman, A. (2015). NMC Horizon Report: 2015 (Museum). The New Media Consortium.

Karpati, A. (2011). Digital literacy in education. UNESCO Institute for Information Technologies in Education

Leonard, J., Mitchell, M., Barnes-Johnson, J., Unertl, A., Outka-Hill, J., Robinson, R., \& Hester-Croff, C. (2018). Preparing teachers to engage rural students in computational thinking through robotics, game design, and culturally responsive teaching. Journal of Teacher Education, 69(4), 386-407. https://doi.org/10.1177/0022487117732317

Li-Grining, C. P. (2007). Effortful control among low-income preschoolers in three cities: Stability, change, and individual differences. Developmental Psychology, 43(1), 208-221. https://doi.org/10. 1037/0012-1649.43.1.208

Luu, K., \& Freeman, J. G. (2011). An analysis of the relationship between information and communication technology (ICT) and scientific literacy in Canada and Australia. Computers \& Education, 56(4), 1072-1082. https://doi.org/10.1016/j.compedu.2010.11.008

Maechler, M., \& Rousseeuw, P. (2019). Finding Groups in Data: Cluster Analysis Extended . Computer software, CRAN Repository

McManus, P., Walmsley, J., Argent, N., Baum, S., Bourke, L., Martin, J., et al. (2012). Rural Community and Rural Resilience: What is important to farmers in keeping their country towns alive? Journal of Rural Studies, 28(1), 20-29. https://doi.org/10.1016/j.jrurstud.2011.09.003

Micklewright, D., Angus, C., Suddaby, J., Gibson, A. S. C., Sandercock, G., \& Chinnasamy, C. (2012). Pacing strategy in schoolchildren differs with age and cognitive development. Medicine and Science in Sports and Exercise, 44(2), 362-369. https://doi.org/10.1249/MSS.0b013e31822cc9ec

Nascimento, K. A. S., Melo, M. B. O., Silva, M. A., Barbosa, J. R., \& Castro-Filho, J. A. (2011). Programa UCA no Estado do Ceará: Caminhos Percorridos, Lições Aprendidas. (Vol. 1, pp. 12071215). Presented at the XXII SBIE - XVII WIE, Aracaju, Brazil: XXII SBIE - XVII WIE Annals.

Nedungadi, P. P., Menon, R., Gutjahr, G., Erickson, L., \& Raman, R. (2018). Towards an inclusive digital literacy framework for digital India. Education + Training, 60(6), 516-528. https://doi.org/10.1108/ ET-03-2018-0061

Nelson, J. M. (2007). Elections, democracy, and social services. Studies in Comparative International Development, 41(4), 79-97. https://doi.org/10.1007/BF02800472

$\mathrm{Ng}$, W. (2012). Can we teach digital natives digital literacy? Computers \& Education, 59(3), 1065-1078. https://doi.org/10.1016/j.compedu.2012.04.016

Park, S. (2016). Digital inequalities in rural Australia: A double jeopardy of remoteness and social exclusion. Journal of Rural Studies. https://doi.org/10.1016/j.jrurstud.2015.12.018

Parry, E., \& Urwin, P. (2011). Generational differences in work values: A review of theory and evidence. International Journal of Management Reviews, 13(1), 79-96. https://doi.org/10.1111/j.1468-2370. 2010.00285.x

Prensky, M. (2001). Digital Natives, Digital Immigrants. On the Horizon, 9(5).

Psacharopoulos, G., \& Patrinos, H. A. (2018). Returns to investment in education: A decennial review of the global literature. The World Bank. https://doi.org/10.1596/1813-9450-8402

Raabe, A. L. A., Brackmann, C. P., \& Campos, F. R. (2018). Currículo de referência em tecnologia e computação:Da educação infantil ao ensino fundamental (2dn ed.). CIEB.

Reimers, F. (1999). Educational opportunities for low-income families in Latin America. Prospects, 29(4), 535-549. https://doi.org/10.1007/BF02736903

Schuller, T. (2004). The benefits of learning: The impact of education on health, family life and social capital. Routledge. https://doi.org/10.4324/9780203390818

Shrout, P. E., \& Fleiss, J. L. (1979). Intraclass Correlations: Uses in Assessing Rater Reliability. Psychological Bulletin, 86(2), 420-428.

Siwatu, K. O. (2007). Preservice teachers' culturally responsive teaching self-efficacy and outcome expectancy beliefs. Teaching and Teacher Education, 23(7), 1086-1101. https://doi.org/10.1016/j. tate.2006.07.011

Türker, P., \& Pala, F. K. (2020). The Effect of Algorithm Education on Students' Computer Programming Self-Efficacy Perceptions and Computational Thinking Skills. International Journal of Computer Science \& Engineering Survey, 3(3), 19-32. https://doi.org/10.21585/ijcses.v3i3.69

Turner, A. (2015). Generation Z: Technology and social interest. The Journal of Individual Psychology, 71(2), 103-113. https://doi.org/10.1353/jip.2015.0021

Unesco. (2016). Education for people and planet: Creating sustainable futures for all (Second.). Paris: Unesco. 
Vernon-Feagans, L., Willoughby, M., Garrett-Peters, P., \& Family Life Project Key Investigators. (2016). Predictors of behavioral regulation in kindergarten: Household chaos, parenting, and early executive functions. Developmental Psychology, 52(3), 430-441. https://doi.org/10.1037/dev0000087

Williams, F., Philip, L., Farrington, J., \& Fairhurst, G. (2016). Digital by Default and the' , 'hard to reach: Exploring solutions to digital exclusion in remote rural areas. Local Economy, 31(7), 757777. https://doi.org/10.1177/0269094216670938

Witte, J. C., \& Mannon, S. E. (2010). The Internet And Social' ' Inequalities (sociology Re-wired) (1st ed., p. 192). Routledge

World Bank. (2018). World Development Report 2018: Learning to Realize Education's Promise\&nbsp;. Washington DC: World Bank. http://journals.openedition.org/ries/6107. Accessed 4 April 2020

Bekker, T., Bakker, S., Douma, I., van der Poel, J., \& Scheltenaar, K. (2015). Teaching children digital literacy through design-based learning with digital toolkits in schools. International Journal of Child-Computer Interaction, 5, 29-38. https://doi.org/10.1016/j.ijcci.2015.12.001

Hu, X., Gong, Y., Lai, C., \& Leung, F. K. S. (2018). The relationship between ICT and student literacy in mathematics, reading, and science across 44 countries: A multilevel analysis. Computers \& Education, 125, 1-13. https://doi.org/10.1016/j.compedu.2018.05.021

Chetty, K., Qigui, L., Gcora, N., Josie, J., Wenwei, L., \& Fang, C. (2018). Bridging the digital divide: measuring digital literacy. Economics: The Open-Access, Open-Assessment E-Journal. https://doi. org/10.5018/economics-ejournal.ja.2018-23

Vargas, F., \& Stenning, K. (2019). Logical Reasoning beyond Classical Logic: An Illustration with Pythagoras Theorem. International Electronic Journal of Mathematics Education, 1(1). https://doi. org/10.29333/iejme/5883

Publisher's note Springer Nature remains neutral with regard to jurisdictional claims in published maps and institutional affiliations.

\section{Authors and Affiliations}

Viviane Brito Nogueira ${ }^{1}\left(\mathbb{0} \cdot\right.$ Diego Gomes Teixeira $^{2}(\mathbb{D}$. Ivan Alisson Cavalcante Nunes de Lima ${ }^{3}$ (1) - Marcus Vinícius Chaves Moreira ${ }^{3}$. Bárbara Sthéphane Caixeta de Oliveira ${ }^{4}(1)$. lago Matheus Bezerra Pedrosa ${ }^{5}(1)$. Jose Wilton de Queiroz ${ }^{6} \cdot$ Selma Maria Bezerra Jeronimo ${ }^{6}[\mathbb{B}$

Selma Maria Bezerra Jeronimo

smbj@cb.ufrn.br

1 Health Sciences Center, Federal University of Rio Grande Do Norte, Natal, Rio Grande do Norte, Brazil

2 Department of Biochemistry, Biosciences Center, Federal University of Rio Grande Do Norte, Natal, Rio Grande do Norte, Brazil

3 Information Technology Department, Federal University of Rio Grande Do Norte, Natal, Rio Grande do Norte, Brazil

4 Ecology Department, Biosciences Center, Federal University of Rio Grande Do Norte, Natal, Rio Grande do Norte, Brazil

5 Nursing Department, Health Sciences Center, Federal University of Rio Grande Do Norte, Natal, Rio Grande do Norte, Brazil

6 Institute of Tropical Medicine of Rio Grande Do Norte, Federal University of Rio Grande Do Norte, Natal, Rio Grande do Norte, Brazil 